' École des Hautes Études en Sciences Sociales (EHESS), Paris, França

yvecohen@free.fr

Yves Cohen'

\title{
POR QUE CHAMAR O SÉCULO VINTE DE O "SÉCULO DOS CHEFES"?
}

\section{UM FENÔMENO DO SÉCULO VINTE}

Uma coisa que me surpreendeu quando eu comecei a trabalhar sobre os quatro países da minha pesquisa (Cohen 2013) - a França, a Alemanha, os Estados Unidos e a União Soviética -, foi que eles haviam conhecido o mesmo fenômeno mais ou menos no mesmo momento. Em cada um deles formou-se, no final do século dezenove e início do século vinte, um novo discurso sobre o comando, sobre o chefe, sobre a autoridade, sobre o domínio das massas, acompanhando a construção de formas hierárquicas novas em todos os domínios. Longe de envolver apenas países totalitários ou autoritários, a emergência dessas práticas, formais e operacionais em alguns casos, e discursivas em outros, ocorreu igualmente nos países liberais e capitalistas. Não se trata apenas da questão da autoridade dos grandes chefes, mas do aumento do valor operacional e simbólico de todos os títulos intermediários de portadores de alguma parcela de autoridade, mesmo nos níveis mais baixos das fábricas, exércitos, administrações ou mesmo da família e da escola. Trata-se de uma maneira de construir e de nomear o social no século vinte.

Uma mudança linguística ocorre em cada um dos países estudados: nos Estados Unidos, a palavra leadership mal existia no final do século XIX. É só nesse novo momento que o termo começa a ser usado na política, na 
educação, na indústria, na ação moral e na psicologia. Woodroow Wilson, um jovem professor de direito e futuro presidente estadunidense tenta, nos anos I89o conceitualizar o termo leadership em política. Em I904, o primeiro autor americano na área de psicologia da "liderança" considera ser este o problema crucial da economia. Em I9I5 um economista vê a administração dos negócios como sendo "a arte de manejar os homens" (the art of handling men) pela qual se formar em leadership (Collins, I9I0; Jones I9I5; Wilson, I952; Terman, I904). Desse ponto de vista, a palavra leadership é menos uma palavra da língua inglesa do que uma palavra estadunidense. De modo ainda mais surpreendente, a velha palavra alemã Führer era usada, ainda no final do século dezenove, apenas para funções menores como a de guia turístico ou de condutor de máquina. O modelo de autoridade é o modelo monárquico. Os primeiros manuais de gerenciamento industrial, na mesma época, dizem que o empreendedor sozinho deve reinar. A partir do começo do século vinte isso se inverte. É o Kaiser que deve ser um bom Führer, o Führer do desenvolvimento. Em I9I3, um historiador liberal declara o seguinte a respeito do Kaiser: "Nós reivindicamos um Führer pelo qual atravessaríamos o fogo" (Emminghaus, I868; Kohlrausch, 2005). Os autores russos também colocam em prática antigas palavras para lhes dar um sentido moderno e mais geral, como vozd, que significa guia ou chefe, e que não deve mais servir apenas para o tzar ou os grandes generais, mas para toda a escala de dirigentes políticos. Mesmo do lado do movimento socialista, escuta-se Lenin exigir em 1902 que o partido social-democrata seja "uma organização de chefes" na qual cada militante seja ele mesmo um chefe (Lenin, 2006; Pobedonostsev, I898). Em francês,a palavra chef assume também um valor geral no início do século vinte. Antigamente ela se referia apenas aos ocupantes do topo das instituições: presidentes, monarcas, generais, empreendedores etc. Sem deixar de funcionar nesse sentido, chef torna-se uma palavra que designa os portadores de autoridade em todos os níveis das administrações e das organizações (Fayol, I9I6; Foch, I903; Saint-Fuscien, 20II). Assim, nas línguas de quatro países diferentes nota-se a busca semelhante de uma nova linguagem hierárquica que permita pensar mais amplamente a sociedade. Ora, em cada um desses países, a passagem para o século vinte é marcada pela afirmação de uma revolução industrial, a instalação de empresas cada vez maiores que empregam um corpo de funcionários cada vez mais numeroso e a formação de sindicatos, eles próprios, de massa. Instala-se uma política de massa organizada por partidos que, às vezes, porém, não detêm mais eles próprios o controle sobre as multidões que amedrontam as elites. A guerra se torna ela mesma de massa, como é já o caso da guerra civil americana, mas, sobretudo, da Primeira Guerra mundial, que conta com um número inaudito de mortos e engaja a "mobilização total" dos diferentes países (Mosse, I990). A escolaridade obrigatória faz da escola uma administração de numerosas parcelas da população. Trata-se de controlar as multidões, de 
fazer com que as massas obedeçam, de orientá-las na boa direção no plano político, no plano produtivo e na guerra, diante de armas de uma potência jamais vista. Faz-se um imenso esforço para convencer as multidões e as massas de que elas têm necessidade de chefes. Este problema é comum a Lenin, a Woodroow Wilson e a Gustave Le Bon, o autor francês de um best-seller internacional publicado em I895, A psicologia das multidões. Na França, surge o projeto de reunir as "qualidades dissociadas" dos chefes para "perceber em sua unidade o tipo humano: chef". Quem o propõe é o fundador da ergonomia francesa e o autor de uma primeira "Psicologia do chefe", em I9I6. Ele se faz ouvir por gerentes que também tinham o projeto de "esboçar a fisionomia dos chefes". Não existem chefes antigos e um chefe moderno. O chefe, como figura simbólica e social, um título oferecido a quem queira se promover em direção aos altos níveis hierárquicos, é um dos traços da modernidade do século vinte. Le Corbusier, um dos principais criadores da arquitetura moderna, era um grande amador de chefes (Cohen, I987). Henry Ford é considerado um dos mais importantes líderes estadunidenses do século vinte (Bogardus, I924).

O chefe como figura sociossimbólica vem preencher o vazio deixado desde fins do século dezoito pela desvalorização irresistível da aristocracia como classe natural de comando e também do rei como modelo de governante. Nos Estados Unidos e nas democracias europeias, não se pode comandar cidadãos como se comandavam servos. No exército, a ameaça de punição não é mais suficiente para manter na linha de fogo as massas de recrutas (Lyautey, I89I). Nas empresas, o gerenciamento à mão de ferro passa a ser desconsiderado também, como mostra o desenvolvimento do taylorismo (Taylor, I957). Empreendem-se programas de educação dos operários para a revolução. O comando se torna uma ciência.

\section{PSICOLOGIA, SOCIOLOGIA}

A psicologia é sem dúvida a ciência social que participa mais ativamente desse movimento. A questão da multidão e do chefe está no fundamento da psicologia social. A obra de Le Bon sobre a psicologia das multidões é imediatamente traduzida em numerosas línguas, inglês, alemão, russo, português (Le Bon, I 895). O ímpeto de transformar as formas de comando e desenvolver o discurso do leadership e do chefe é um fenômeno multiplamente nacional. Mas é também um fenômeno transnacional e de circulação: circulação entre os países, mas, também, entre os domínios de atividade e de saber (Raj, 2007; Cohen, 20Io). Le Bon é adaptado a todas as situações possíveis. Quem entre os responsáveis em todos os domínios não foi um leitor de Le Bon no início do século vinte? A leitura de A psicologia das multidões é fortemente perceptível na segunda parte da obra Que fazer?, de Lenin. Diz-se que Hitler ofereceu a primeira edição de A psicologia das multidões a Mussolini quando ambos se 
encontraram pela primeira vez. Louis Renault, o fundador da empresa automobilística de mesmo nome, tinha a obra como livro de cabeceira (Rhodes, I970: 63-64, 73 e I46). De Gaulle escreveu desde os anos I920 artigos sobre o chefe muito inspirados em Le Bon, cujo salão parisiense ele frequentava (De Gaulle, I998). Circulando, este livro se torna a fonte de uma linguagem internacional sobre o condutor e a multidão. Mas não é apenas a psicologia social que circula. A psicologia experimental também atravessa o Atlântico, da França em direção aos Estados Unidos.

O primeiro artigo do mundo sobre psicologia da liderança foi escrito por Lewis Terman em I904: "A preliminary study in the psychology of leadership". Para construir um teste que permita detectar o líder de um pequeno grupo de crianças escolarizadas, Terman toma emprestado o teste de sugestionabilidade do psicólogo francês Alfred Binet, que publicou em I 900 um livro que deu o que falar sobre A sugestionabilidade (Terman, I904; Binet, I900). Emprestando este teste, Terman o transforma, tal como é de praxe em todo fenômeno de circulação. O teste se torna então um teste de liderança; ao invés de serem designados previamente como fazia Binet, os líderes aparecem ao longo do estudo; os grupos são de quatro e não de três crianças; mas Terman coloca o mesmo número de questões, inclusive sob a forma de armadilha. Ainda que tenha sido importado nos Estados Unidos, o trabalho de Binet já havia sido ele mesmo produzido na França numa relação com a psicologia americana. Binet serve-se, em seu livro, da palavra inglesa leader para designar os chefes desses grupos. Ele é, ademais, membro do comitê de redação de uma revista americana, The Psychological Review. A circulação faz de fato um movimento circular: dos Estados Unidos em direção à França e de volta aos Estados Unidos. Binet pensa, aliás, sua psicologia experimental como uma psicologia também social, já que a considerava a primeira forma de psicologia dos grupos.

A sociologia também se engaja profundamente na fabricação da figura do chefe do século vinte. É nessa conjuntura de grande preocupação com a questão da autoridade e do chefe que Max Weber e Émile Durkheim formulam os fundamentos de suas sociologias. Essa questão está no centro de suas concepções daquilo que faz uma sociedade. Weber começa a formular sua sociologia da dominaçãoantes da guerra de I9I4 a I9I8. Em I9I7, no momento em que o Kaiser Guilherme Segundo demonstra sua profunda insuficiência como chefe de guerra, Weber entra na política de maneira sistemática. Ele torna-se quase ministro da constituição republicana no final de I9I8. Sua reflexão é ao mesmo tempo a reflexão de um sociólogo e a de um político muito preocupado com o destino da Alemanha (Weber, 2009, 20I I). Pode-se dizer que sua sociologia da dominação tenha sido fortemente influenciada por isso. De um lado, Weber temia muito o império que a burocracia poderia assumir sobre os negócios públicos. De outro, ele era profundamente um democrata, mas desconfiava muito da democracia alemã, e mais precisamente de sua capacidade 
de selecionar os chefes de que a Alemanha tinha grande necessidade naquele momento. É nessa conjuntura que Weber concebe a idéia de um presidente eleito diretamente pelo povo e que fosse dotado "das qualidades carismáticas profundas que fazem os chefes" (Weber, 20II). Ainda que tenha sido publicada quando Weber ainda era vivo e também após sua morte, sua teoria do chefe carismático ficou um tanto quanto restrita à Alemanha e ao domínio da sociologia até o final dos anos I930, quando suas obras passam a ser disseminadas por sociólogos alemães, frequentemente judeus, que se dispersam pelo mundo e particularmente nos Estados Unidos. Vê-se bem que essa teoria só pode ser plenamente compreensível no seu tempo, mas também que ela é plenamente atuante nesse período (Bendix, I956; Michels, I9I I).

Para as ciências durkheimianas, da mesma forma, a autoridade está no princípio do social. Trata-se de uma "autoridade moral" que se exerce sobre cada ato individual e que se exerce, entre outras formas, através das ordens. Esta autoridade provém das "crenças" e das "práticas sociais" constituídas que "se impõem" a cada um. Este é, para Durkheim, o problema central da sociologia. Como ele afirma em As formas elementares da vida religiosa: "O problema sociológico - se é que podemos dizer que existe um problema sociológico - consiste em buscar nas diferentes formas de coerção exterior as diferentes formas de autoridade moral que a elas correspondem, e em descobrir as causas que determinaram estas últimas". E essas forças morais falam ao homem, segundo ele, "no tom do comando" (Durkheim, I990: 298).

Essas ciências sociais alimentam e reforçam, portanto, uma visão hierárquica da sociedade na qual uma das formas principais do vínculo social é a obediência de uns às ordens ou às prescrições dos outros.

Nos Estados Unidos, é toda uma nova disciplina universitária e profissional que se forma desde os anos I920 para avaliar as qualidades ou os traços da personalidade dos melhores líderes (Van Fleet \& Yukl, I989). É surpreendente, contudo, notar a dispersão desses estudos. Desde I930 levantam-se dúvidas sobre a capacidade da psicologia de identificar de maneira certeira as qualidades que fazem os bons chefes (Metcalf, I93I: 4). Como se constata, até mesmo a inteligência, que é objeto de muitas pesquisas, não chega a se tornar um dos critérios mais importantes. O líder é apenas um pouco mais inteligente do que a média do grupo. Se não se podem selecionar os líderes por suas qualidades, será que seria possível fazê-lo pelo seu comportamento? O behaviorismo ganha espaço com o fracasso da psicologia dos traços da personalidade, sem conseguir se mostrar mais convincente segundo seus especialistas (Jago, I982: 315). A partir dos anos I930 diz-se que a qualidade da liderança não depende tanto do líder, mas dos seguidores e também da situação (Metcalf, I93I: 3). A liderança seria então um triângulo formado pelo encontro entre os líderes, os seguidores e a situação. Para alguns, trata-se de um fenômeno objetivo; para outros, a definição da situação por seus participantes faz parte da situação e, mais do que 
isso, ela contribui para constituí-la (Case, I933: 5IO-5I3). É surpreendente que o mesmo discurso tenha se mantido vigoroso mesmo depois que o behaviorismo e a teoria da situação colocaram em cheque a existência de qualidades universais da liderança. Pode-se supor então que uma das razões fundamentais desse discurso não é o estudo científico, mas sim o reforço dos líderes. O que importa é lhes dizer que eles são líderes e que têm razão em sê-los.

Não estamos, pois, diante de uma liderança objetiva, antiga ou a-histórica, mas de uma liderança construída deliberadamente desde o início do século vinte como objeto de estudo, de discurso e de práticas organizacionais e sociais (Grint, I997, 2000). A sociedade inteira está envolvida uma vez que o social é formado por hierarquias de todos os tamanhos animadas em todos os níveis por chefes e por líderes. Nesse quesito Lenin partilha da mesma representação dos ideólogos da liderança. Para defender sua concepção do partido contra os comunistas alemães que criticam "a ditadura dos chefes", o dirigente bolchevista generaliza sua proposição em I 920 na obra Esquerdismo: doença infantil do comunismo: "Todos sabem que as massas se dividem em classes [...]; que as classes são, geralmente e na maioria dos casos (pelo menos nos países civilizados modernos), dirigidas por partidos políticos; que os partidos políticos são dirigidos, via de regra, por grupos mais ou menos estáveis de pessoas que reúnem o máximo de autoridade, de influência, de experiência, alçadas pela via da eleição aos cargos de maior responsabilidade e chamadas de chefes [a palavra utilizada em russo é vozd no plural]" (Lenin, I920: s.p.). Todavia, são os Estados Unidos e a Alemanha de Weimar os principais países nos quais se desenvolve uma psicologia da liderança. Já a Alemanha nazista, inspirada por seu Führer único, não tem nada a fazer de uma psicologia. A União Soviética, por seu turno, desconfia dos círculos de psicólogos ligados aos debates travados no estrangeiro. Além do mais, ela espera que a teoria marxista responda a todas as necessidades do pensamento. Na França, a psicologia das multidões impediu a formação de uma psicologia especializada do chefe e do comando. Esta ganhará força somente depois da Segunda Guerra Mundial.

\section{TRAJETÓRIAS NACIONAIS}

Como se pode notar, cada país vê se desenvolver uma trajetória nacional para esta preocupação com a questão do comando e do chefe. Todos têm em comum uma mesma fórmula que é dita da mesma maneira em todas as línguas em jogo: nós temos necessidade de chefes (Cohen, 20I2). Mas há variações entre os países: depois da derrota da Alemanha na Primeira Guerra Mundial, ouve-se um "grito em direção ao Führer" ("ein Schrei nach dem Führer"). Um autor próximo dos nazistas diz no início dos anos I930: "A guerra só pôde terminar em I 9 I 8 do jeito que terminou porque nos faltou um grande chefe político" (Geyer, I926: Io; Grabein, I933: 5). Mais do que a necessidade de Führers no plural, é a 
necessidade de um Führer no singular que se exprime. Mas há que se precisar que a discussão começou antes que existisse um partido nacional-socialista: é antes um debate da sociedade alemã com ela mesma, como é também o caso em outros países. Assim, no mundo industrial, desenvolvem-se formações sobre como conduzir dos homens. Os empregadores estabelecem centros de formação para os engenheiros e também para os operários qualificados. Trata-se de ensinar técnicas de condução dos homens, tanto no plano psicológico quanto no plano técnico ou no plano administrativo. Os testes da psicotécnica são introduzidos nas fábricas para selecionar e orientar os operários e os técnicos. Todo um debate muito vivo se desenvolve na Alemanha para saber até que ponto a psicologia poderia servir diretamente aos interesses do capital ou como ela poderia ser um instrumento justo de regulação do trabalho (Nolan, I994; Rabinbach, I995). Quando Hitler chega ao poder, essas formações de Menschenführung são reorganizadas no quadro do novo regime. Cada fábrica deve ter o seu Führer. O Führerprinzip deve reinar ao mesmo tempo na sociedade e na economia. Mesmo se se observa certa resistência nas empresas da parte dos empreendedores e gerentes, o Führerprinzip se instala. Ele não vale senão para os alemães de raça. Cada alemão pode se tornar um Führer, nem que seja dirigindo o trabalho de judeus e outras sub-raças, como se passará durante a guerra. Mas mesmo para os alemães, a condição para participar do Führerprinzip é de se subordinar inteiramente ao Führer supremo. Este não pode senão ser Hitler, que não é o representante do povo, mas o próprio povo (Jouanjan, 2006: I48-I49; Neesse, I940: 54). A Alemanha se torna uma nação de chefes: todos devem a eles obedecer e, com a condição de serem alemães, todos devem comandar.

A trajetória soviética é marcada por uma tensão entre a democracia e o governo dos chefes. Na realidade, a democracia foi uma fachada, seja o centralismo democrático decretado pela Terceira Internacional em I9I9 para todos os partidos comunistas do mundo ou a constituição dita "democrática" de I936 na qual o partido comunista é reconhecido como força dirigente do país, escapando assim a todo controle democrático. Desde I 922 quadros do partido vêm à Moscou unicamente para obedecer às ordens de Stalin. Eles estão "nas mãos de Stalin", como disse um deles (Khlevniuk, 2008). Quando a desordem reina numa organização, diz-se que é porque "não há um chefe" e que tudo iria melhor se houvesse um secretário geral (que é o título de Stalin) (Pascal, I982: I I). A língua russa tem uma palavra para se referir ao guia equivalente a de Duce ou Führer. Lenin faz uso dela para dizer que todo membro do partido social-democrata deve ser um vozd. Depois a palavra é utilizada de maneira muito intensa pelo próprio Lenin. Mesmo se os bolchevistas dizem recusar todo poder pessoal, é bem ele que se instala desde I9I7 com a preeminência não disputada de Lenin sobre todos os seus outros camaradas. Mas é sobretudo pela tomada de todos os poderes por Stalin em I 928 e I 929 que a atribuição 
do título de Vozd passa a ser feita sistematicamente (Davies, 1997). Aliás, hierarquias de toda ordem se desenvolveram no país I9I7. Na economia e também no aparelho administrativo do partido e do Estado, vê-se desdobrar uma “organização funcional”, imitando as empresas americanas. Esta organização multiplica as funções de conselho que não têm um papel hierárquico direto. O partido exerce, aliás, cada vez mais seu papel dirigente. Outras hierarquias (o controle do Estado, a polícia política e a justiça) se inserem ainda no seio das instituições sociais. O conjunto das hierarquias paralelas se torna tão complexo que o governo stalinista suprime a organização funcional em I934 e declara a necessidade de se apoiar sobre "os chefes", o "nachal'stvo" (Shearer, I996). A partir de então, a palavra nachal'nik se espalha por toda a sociedade. Nos filmes soviéticos dos anos I930 e depois, ouve-se frequentemente " $D a$, tovarichtch nachal'nik", "Sim, camarada chefe". Tudo se mede a partir de agora em função da subordinação às ordens de Stalin.

Nos Estados Unidos o desenvolvimento do leadership se tornou progressivamente um assunto de profissionais. O primeiro colóquio mundial consagrado unicamente ao leadership ocorre em I927. Mais orientado à liderança industrial, ele reúne gerentes, especialistas do gerenciamento, oficiais superiores, representantes das grandes escolas de comércio, especialistas de educação e psicólogos. Isso marca o caráter multidisciplinar da pesquisa sobre a liderança, colocando lado a lado universitários e representantes da economia e do exército; mas marca, mais ainda, o interesse amplamente suscitado pelo aparecimento dessa noção que parece oferecer uma chave de interpretação da sociedade e ao mesmo tempo um meio de ação (Moore, I927). A propósito, uma grande parte dos estudos de psicologia e de sociologia sobre a liderança faz-se no contexto escolar. Com efeito, uma idéia amplamente difundida é a de que o ensino deve permitir selecionar líderes desde a infância e formá-los para a liderança, ao mesmo tempo em que para serem úteis. Detectar crianças-líderes torna-se uma aposta nacional (Russel, I930: 314). Mais amplamente, nos estudos de psicologia, a criança é considerada como o modelo do adulto. A produtividade dessa nova cultura da liderança é marcada por um acontecimento em escala nacional, que é a eleição de Franklin Roosevelt à presidência dos Estados Unidos em 1932, no momento mais dramático da Grande Depressão. Muito mais do que seus predecessores, em seu pronunciamento inaugural Roosevelt se apresenta como o salvador em quem o povo americano confiou a liderança do país. Em doze minutos, a palavra "leadership" aparece sete vezes. Primeiro presidente americano a ser acompanhado por um conselheiro em relações públicas, Roosevelt é também o inventor de "bate-papos ao pé da lareira" ("fireside chats"), que ele pratica regularmente ao longo de suas presidências. Trata-se de falar com cada um e não a todos. A operação depende de técnicas de comunicação. Roosevelt coloca um dente falso antes de cada gravação para evitar que se ouça um ligeiro assobio devido à falta de um dente em sua 
dentição. Sabendo que sua voz de bate-papo é diferente de sua voz ordinária, ele impede a difusão radiofônica de alguns de seus discursos naturais (Schivelbusch, 2006: 56-58). Em todo caso, essa deliberada apresentação como líder é uma maneira de conciliar a liderança e a democracia, como na proposição weberiana, mas ao contrário da versão nazista para a qual o advento do Führer supõe a destruição da democracia (Weber, 20I I).

A preocupação com o chefe e o comando na França não é menos profunda que nos três primeiros países evocados, mas ela é sem dúvida mais difusa, menos estrondosa e menos encarnada. Reformar o comando no exército e na fábrica, refletir sobre o papel do presidente do conselho em relação ao parlamento, desenhar a figura do chefe em geral e aquela do grande chefe em particular, proclamar que as hierarquias são naturais são atos que ocupam cada vez mais o mundo a partir dos anos I 890 (Barthélemy, I906). Duas figuras se destacam, primeiro aquela de Gustave Le Bon, de quem já falei, que era um personagem público, diretor de uma célebre coleção de literatura científica, polígrafo que escrevia sobre todos os assuntos, inclusive o átomo, organizador de um salão frequentado pelas elites da Terceira República. Edepois aquela de Hubert Lyautey, marechal da França em I92 I, cuja influência foi imensa e quem para muitos franceses foi o grande exemplo do Chefe (Tarde, I959). Um pequeno livro de Lyautey, publicado em I89 , marcou, na França, os primórdios dessa reflexão moderna sobre o chefe e o comando. Trata-se do Papel social do oficial: tendo em vista o então recente alistamento obrigatório no serviço militar, pelo período de três anos, Lyautey pede que os oficiais conheçam melhor os seus homens do que os seus cavalos. Ele pensa na batalha, mas, também, no papel de pacificação social que cabe ao exército. Esta obra é imediatamente seguida de outras de mesmo título e de muitas do tipo "O papel social do engenheiro" - veja-se, por exemplo, Cheysson (I897), Ebener (I90I), Donop (I908), Foulon (I908) e Lamirand (I932). O "papel do chefe" é discutido tanto na empresa quanto no Estado, no exército como na escola. Após a Primeira Guerra Mundial, ser um chefe torna-se uma honra social invejada por alguns, mas também motivo de zombaria para os que desprezam as formas de autoridade. A atmosfera se torna mais tensa na França e em outros países a partir de I933 e I934, como se se tratasse de um fenômeno mundial. Em I934, manifestações de extrema direita inquietam todo o espectro político. A Frente Popular de esquerda ganha as eleições em I936. Após um grande movimento de greve, a temática do chefe, bastante defendida pelos liberais,se reforça nas fábricas e em política. Tudo isso termina na guerra. Esta é uma história de populações mobilizadas, de territórios ocupados, de mortes de massa, de genocídios, de bombardeamento de civis, e é também uma história de chefes: na França, o Chefe de Estado francês, o marechal Pétain, opõe-se ao chefe da França livre, o general de Gaulle. 


\section{O ESTUDO DAS PRÁTICAS}

Toda a primeira parte de meu livro é consagrada à exposição da emergência dessa nova cultura, dessas práticas discursivas e dessas novas práticas hierárquicas. O conjunto se enquadra bem no período entre I990 e I940, mas traça também uma trajetória que, pode-se dizer, vai até os anos 68, isto é, até I 968 e os anos seguintes. Desde o início do século vinte, uma crise da autoridade é diagnosticada nesses países, desencadeando sempre a mesma resposta: mais chefes. E, efetivamente, o enquadramento hierárquico das empresas, das administrações e, em geral, das organizações muito se intensificou, multiplicando aquilo que em francês chamamos de os "quadros superiores" (Barnard I938, I997; Boltanski I982). O fenômeno do século vinte não é, portanto, apenas o que apareceu mais fortemente, isto é, o culto do chefe, com suas formas extremas na Alemanha, na Itália e na União soviética. É também uma modalidade de transformação do social em todos os domínios de atividade.

As práticas dos chefes se transformam também no decorrer deste século. A segunda parte do livro é baseada nos arquivos que se mantêm o mais próximo das pessoas a fim de seguir suas ações em detalhes. Três capítulos dizem respeito à gestão industrial. Os dois capítulos franceses acompanham o diretor das fábricas Peugeot durante os anos I930. Eles são escritos a partir dos arquivos pessoais deste engenheiro: notas de serviços, a correspondência em que justifica e explica sua ação em particular à família Peugeot, manuscritos de conferências, várias autobiografias profissionais inéditas. Este diretor é um dos grandes engenheiros tayloristas na França, um dos primeiros organizadores da linha de montagem dos automóveis (Cohen, 200I). Ele conduz sua ação em função de planos. Ora, o plano é em geral o assunto por excelência do chefe, ele detém uma autoridade na medida em que é concebido para mobilizar os esforços de cada um em vista de um projeto comum. Esses arquivos permitem, portanto, uma boa exploração do que é conceber planos e trabalhar em função deles. Há outro aspecto que é objeto de outro capítulo. Estamos no início da era dos gerentes (Berle \& Means, I932; Burnham, I94I; Rizzi, I976). A gestão industrial se faz cada vez mais à distância. Ora, este engenheiro não cessa de proclamar que o diretor da produção deve conservar uma "prática de ateliê" e permanecer em contato permanente com todos os participantes, desde os operários até os quadros superiores. A reflexão sobre o interesse e as técnicas do comando à distância é uma das características desta época.

Um primeiro capítulo russo é baseado numa fonte frequentemente encontrada nos arquivos soviéticos, mas pouco encontrada em outros lugares: os estenogramas das reuniões entre os quadros dirigentes. Pode-se seguir então quase ao vivo a ação que consiste na troca de argumentos para orientar a ação nos escritórios e nos próprios ateliês. Ora, uma parte desses estenogramas é produzida justamente a partir das discussões sobre o que é ser um chefe na 
construção do socialismo. Podemos então acompanhar essas discussões na fábrica Putilov de Leningrado, uma grande usina de mecânica fundada na época dos tzares. Os estenogramas utilizados são centrados no ano de I930, ao longo do qual é possível perceber dois fenômenos: de um lado, os efeitos do ataque de Stalin aos engenheiros ditos "especialistas burgueses", por terem sido formados sob o antigo regime, e de outro, o esforço dos quadros dirigentes da fábrica para se tornarem gerentes eficazes, se inspirando nos Estados Unidos, só que em meio às condições extremamente difíceis da União Soviética.

O último capítulo é centrado em Stalin. Ele é baseado em seus arquivos de trabalho, suas cartas manuscritas de comando no início dos anos Io39, suas notas, seus rascunhos, seus rabiscos quando ele estava refletindo sobre alguma coisa, todo o seu material de informação em suma. Stalin não era apenas o objeto de seu próprio culto, mas um chefe praticante muito experimentado, um mestre do comando indiferente a qualquer preocupação democrática. Em primeiro lugar, Stalin ensinava a seus próximos companheiros como ser um chefe. Podemos seguir todo o seu trabalho de ensino da ação através das suas cartas e daquelas que ele recebia de seus amigos, em particular a partir de uma inspeção que ele faz na Sibéria em janeiro de I928 para retirar à força a farinha dos camponeses. O coração dos seus ensinamentos é a política que se diz da "preferência repressiva", isto é, aquela segundo a qual a solução dos problemas que sempre é favorecida é a de uma repressão orientada ao mesmo tempo contra uma fração da população e contra os membros do partido que hesitam frente a esta política. O capítulo segue assim outras ações conduzidas por Stalin, como a concepção de uma lei que, em plena onda de fome no sul da Rússia e da Ucrânia, condena à morte ou a no mínimo dez anos de campo de concentração aqueles que violam a propriedade socialista: nenhum mínimo é indicado por quantidade roubada. Como os camponeses famintos se serviam de sua própria produção, eles foram presos em função desta lei que se chamou "a lei das três espigas de milho". Examino ainda como Stalin dirige pessoalmente o terror de massa dos anos I937 e I938.

Este livro é, portanto, um estudo da fabricação ativa da sociedade como reunião de hierarquias dirigidas por chefes. Esses chefes são quase que totalmente homens. Todo esse discurso é dito estritamente no masculino, como se ser chefe fosse um atributo normal da virilidade. Pouquíssimos livros associam a liderança às mulheres ou contêm capítulos a respeito - Espey (I9I5) foi o único livro que pude identificar a este respeito nos quatro países estudados. Quando se considera o comando exercido por mulheres, ele é exclusivamente pensado como se exercendo apenas sobre outras mulheres e não sobre homens (Tead, I935). É o que já ocorria nas fábricas têxteis francesas no século XIX com as "contramestras". O mundo dos chefes é aquele em que as relações se dão entre pessoas do mesmo sexo. E, a propósito, a frequência de assédio sexual entre chefes e subordinadas é bem documentada nas recomendações 
de reserva e de contenção encontradas em diversos manuais (ver, por exemplo, Pezeu, I920: I33).

Uma idéia subjacente é a de que a hierarquia é natural, ainda que a antropologia tenha mostrado que as sociedades mais arcaicas trabalhavam ativamente para evitar a formação de hierarquias perenes. Os chefes não deveriam procurar se instalar definitivamente como chefes (Clastres, 2007). O século vinte acentuou fortemente uma via contrária, como se todo grupo social, independentemente de qual fosse o tipo de agrupamento, não pudesse não ter o seu chefe. A psicologia social disse às multidões que elas tinham necessidade de mestres, de chefes, de condutores. Com exceção de alguns libertários, tal discurso foi retomado por todos, desde o campo político até os empreendedores e gerentes. Atualmente esse discurso é bem mais difícil de ser sustentado. O século vinte não teria efetivamente terminado? Não encontramos hoje em dia novamente o esforço para que não se criem chefes? Num certo número de países, as empresas buscam, como elas mesmas dizem, "esmagar as hierarquias", isto é, reduzir a quantidade de níveis hierárquicos. Mas são especialmente os movimentos sociais que experimentam novas formas de ação e de sociabilidade militante horizontal. Numerosos movimentos de protesto buscam antes de qualquer coisa a cooperação e a igualdade. Podemos acompanhar essa busca desde pelo menos I968. Ela está presente no movimento antiglobalização, por exemplo, quando de sua intervenção no fórum mundial de Porto Alegre. Eu assisti à greve da USP em 2009: a reitoria ficou muito inquieta com o fato de não existir alguém com quem falar. Em nível mundial, uma nova etapa foi percorrida com o movimento democrático na Tunísia em 20Io, seguido da "primavera árabe" e de todos os outros movimentos. Nesse sentido, as Jornadas de Junho no Brasil foram uma experiência emblemática. Tratou-se de se dirigir ao poder através da presença na rua, de apresentar demandas precisas, recusando não apenas partidos e chefes, mas também toda vontade de tomar o poder. Além disso, esses movimentos são urbanos, têm características estéticas de apresentação corporal comuns e se apoiam em técnicas de comunicação que favorecem a horizontalidade e a agilidade. Ou seja, mesmo que o apelo ao chefe não tenha desaparecido completamente, poderíamos pensar que entramos num século que não será como o século vinte, isto é, um século de chefes. 
Yves Cohen é historiador e professor na École des Hautes Études en Sciences Sociales, em Paris. Publicou em 2013 Le siècle des chefs: une histoire transnationale du commandement et de l'autorité (I890-I940), uma história das práticas de autoridade, da figura do chefe e do leadership como cultura e discurso na França, Alemanha, União soviética e Estados Unidos. A sua pesquisa atual é sobre uma história transnacional das práticas da influência e sobre os movimentos sociopolíticos dos anos 2010. 


\section{REFERÊNCIAS BIBLIOGRÁFICAS}

Barnard, Chester I. (1938). The functions of the executive: wild ideas about organization and administration. Cambridge: Harvard University Press.

Barnard, Chester I. (I997) [I94I]. The nature of leadership. In: Grint, Keith (org.). Leadership: classical, contemporary, and critical approaches. Oxford: Oxford University Press, p. 89-I I I.

Barthélemy, Joseph. (1906). Le rôle du pouvoir exécutif dans les Républiques modernes. Paris: Giard et Brière.

Bendix, Reinhard. (1956). Work and authority in industry: ideologies of management in the course ofindustrialization. Berkeley: University of California Press.

Berle, Adolf \& Means, Gardiner C. (I932). The modern corporation and private property. Nova York/Chicago: Commerce Clearing House.

Binet, Alfred. (I900). La suggestibilité. Paris: Schleicher.

Bogardus, Emory S. (1924). Fundamentals of social psychology. New York: The Century Co.

Boltanski, Luc. (I982). Les cadres: la formation d'un groupe social. Paris: Minuit.

Burnham, James. (I94I). The managerial revolution. Nova York: John Day Co.

Case, Clarence M. (I933). Leadership and conjuncture: a sociological hypothesis. Sociology and Social Research, I7, p. 510-5i3.

Cheysson, Émile. (I897). Le rôle social de l’ingénieur. Paris: Librairie Guillaumin et Cie.

Clastres, Pierre. (2007). A sociedade contra o Estado: pesquisas de antropologia política. São Paulo: Cosac Naify.

Cohen, Jean-Louis. (I987). Bat'a (Tomáš) (I876-I932). In: Lucan, Jacques (org.). Le Corbusier, une encyclopédie. Paris: Centre Georges Pompidou, p. 62-67.

Cohen, Yves. (2013). Le siècle des chefs: une histoire transnationale du commandement et de l'autorité (I890-I940). Paris: Éditions Amsterdam.

Cohen, Yves. (20I2). Le "besoin de chefs" au début du XXe siècle: un tour d'horizon international entre business, po- 
litique et psychologie. In: Godelier, Éric et al. (dir.). Pensée et Pratiques du Management en France. Inventaire et Perspectives I ge-2 Ie siècles. Disponível em <http://mtpf.mlab-innovation.net/fr/PDF\%20OK/Cohen\%2oVF.pdf $>$. Acesso em 26 out. 2015.

Cohen, Yves. (2010). Circulatory localities: the example of Stalinism in the I930s. Kritika: Explorations in Russian and Eurasian History, I I/I, p. I I-45.

Collins, James H. (I9I0). The art of handling men. Philadelphia: Henry Altemus Co.

Davies, Sarah. (I997). The "cult" of the vozhd: representations in letters from I934-I94I. Russian History, 24/I-2, p. I3I-I 47 .

De Gaulle, Charles. (1998). Préparer la guerre, c'est préparer des chefs. In: Le fil de l'épée et autres récits. Paris: Plon, p. 585-593. [Publicado originalmente como: L'action de guerre et le chef. Revue Militaire Française, I mar. 1928].

Donop, Général Raoul-Marie. (I908). Le rôle social de l'officier. La Réforme Sociale, Société d'économie sociale, Paris, I maio. Disponível em <http://visualiseur.bnf.fr/ CadresFenetre?O=NUMM-5443779\&M=tdm $>$. Acesso em 29 nov. 2015.

Durkheim, Émile. (I990) [I9I2]. Les formes élémentaires de la vie religieuse. Le Système totémique en Australie. Paris: PUF. Ebener, Lieutenant-Colonel. (I9oI). Le rôle social de l'officier. Paris: Charles-Lavauzelle.

Emminghaus, Arwed. (I868). Allgemeine Gewerkslehre. Berlin: Herbig.

Espey, Clara E. (I9I5). Leaders of girls. Nova York/Cincinnati: The Abingdon Press.

Fayol, Henri. (I9I6). Administration industrielle et générale. Bulletin de la Société de l'Industrie minérale, Io, p. 5-I64.

Foch, Général Ferdinand. (1903). Les principes de la guerre. Paris: Berger-Levrault.

Foulon, Léon. (1908). Le rôle social de l'ingénieur moderne. Reuue Industrielle de l'Est, Nancy, p. I-9.

Geyer, Curt. (1926). Führer und Masse in der Demokratie. Berlim: Dietz. 
Grabein, Paul. (1933). Ewiges Deutsches Volk. Eine Geschichte deutscher Führung. Leipzig: Grethlein \& Co.

Grint, Keith (org.). (1997). Leadership: classical, contemporary, and critical approaches. Oxford: Oxford University Press, I997

Grint, Keith. (2000). The arts of leadership. Oxford: Oxford University Press.

Jago, Arthur G. (1982). Leadership: perspectives in theory and research. Management Science, 28/3, p. 315.

Jones, Edward D. (I9I5). The relation of education to industrial efficiency. American Economic Review, 5/I, Suplemento, p. 209-226.

Jouanjan, Olivier. (2006). Justifier l'injustifiable. Astérion, 4. Disponível em <https://asterion.revues.org/643>. Acesso em 24 out. 2015.

Khlevniuk, Oleg. (2008). Master of the house: Stalin and his inner circle. New Haven: Yale University Press.

Kohlrausch, Martin. (2005). Der Monarch im Skandal: die Logik der Massenmedien und die Transformation der wilhelminischen Monarchie. Berlin: Akademie Verlag.

Lamirand, Georges. (1932). Le rôle social de l'ingénieur. Scènes de la vie d'usine. Paris: Desclée et Cie.

Le Bon, Gustave. (I895). Psychologie des foules. Paris: PUF.

Lenin, Vladimir Ilich. (2006). Que fazer? São Paulo: Martins Fontes.

Lenin, Vladimir Ilich. (I920). Esquerdismo: doença infantil do comunismo. Disponível em <http://pcb.org.br/portal/docs/ esquerdismo.pdf $>$. Acesso em 27 out. 2015.

Lyautey, Hubert (I89I). Du rôle social de l'officier. Revue des deux mondes, CIV/I5, p. 443-459.

Metcalf, Henry C. (I93I). Business leadership. New York: Pitman.

Michels, Robert. (I9II). Zur Soziologie des Parteiwesens in der modernen Demokratie. Untersuchungen über die oligarschischen Tendenzen des Gruppenslebens. Leipzig: W. Klinkhardt. Moore, Bruce V. (I927). The May conference on leadership. Personnel Journal, 6, p. I24-I 28. 
Mosse, George L. (I 990). Fallen soldiers: reshaping the memory of the World Wars. Nova York: Oxford University Press. Neesse, Gottfried. (1940). Führergewalt, die Entwicklungund Gestaltung der hoheitlichen Gewalt im Deutschen Reiche. Tübingen: JCB Mohr.

Nolan, Mary. (1994). Visions of modernity: American business and the modernization of Germany. Oxford: Oxford University Press.

Pascal, Pierre. (1982). Russie I927: mon journal de Russie. Lausanne: L'Age d'Homme.

Pezeu, Pierre. (I920). Les hommes qu'il nous faut pour organiser la production. Paris: Payot.

Pobedonostsev, Konstantin P. (1898) [1896]. Reflections of a Russian statesman. Trad. Robert Crozier Long. Londres: G. Richards.

Rabinbach, Anson. (I995). La psychologie industrielle dans l'Allemagne de Weimar, entre psychotechnique et politique: le cas d'Otto Lipmann. In : Cohen, Yves \& Baudouï, Rémi (orgs.). Les chantiers de la paix sociale, I900-I940. Fontenay-aux-Roses: ENS-Éditions Fontenay Saint-Cloud, p. I 27-I56.

Raj, Veja Kapil. (2007). Relocating modern science: circulation and the construction of knowledge in South Asia and Europe, I650-I900. Houndsmills: Palgrave Macmillan.

Rhodes, Anthony. (I970). Louis Renault: a biography. Nova York: Harcourt, Brace \& World.

Rizzi, Bruno. (1976). L'URSS: collectivisme bureaucratique (La propriété de classe). Originalmente publicado como primeira parte de La bureaucratisation du monde (I939). Paris: Champ Libre.

Russel, James E. (1930). The educational paradox: an American solution. Teachers College Record, 31/4, p. 307-3 I9.

Saint-Fuscien, Emmanuel. (20I I). À vos ordres? La relation d'autorité dans l'armée française de la grande guerre. Paris: Éd. de l'EHESS.

Schivelbusch, Wolfgang. (2006). Three new deals: reflections on Roosevelt's America, Mussolini's Italy, and Hitler's Germany, I933-I939. Nova York: Metropolitan Books. 
Shearer, David R. (I996). Industry, state, and society in Stalin's Russia, I926-I934. Ithaca: Cornell University Press.

Tarde, Guillaume de. (I 959). Lyautey: le chef en action. Paris: Gallimard.

Taylor, Frederick Winslow. (I957) [I9I I]. Princípios de administração científica. São Paulo: Atlas.

Tead, Ordway. (I935). The art of leadership. Nova York: McGraw-Hill.

Terman, Lewis M. (1904). A preliminary study in the psychology and pedagogy of leadership. Pedagogical Seminar, II, p. 4I3-45I.

Van Fleet, David D. \& Yukl, Gary A. (I989). A century of leadership research. In: Rosenbach, William E. \& Taylor, Robert L. (orgs.). Contemporary issues in leadership. Boulder: Westview Press, p. 64-90.

Weber, Max. (2009). Economia e sociedade: fundamentos da sociologia compreensiva. Brasília: Ed. UnB.

Weber, Max. (20I I). Ciência e política: duas vocações. São Paulo: Cultrix.

Wilson, Woodrow. (1952). Leaders of men. Princeton: Princeton University Press. [A partir de um manuscrito de I890]. 
Palavras-Chave

História da autoridade;

Culto do chefe;

Liderança;

História das práticas;

Transformação social.

\section{POR QUE CHAMAR O SÉCULO VINTE DE O "SÉCULO DOS CHEFES"?}

\section{Resumo}

Este texto aborda o fenômeno da chefia entre o final do século XIX e século XX na França, a Alemanha, os Estados Unidos e a União Soviética. Trata-se do surgimento de um novo discurso sobre o comando, sobre o chefe, sobre a autoridade, sobre o controle das massas. Tal discurso, que emerge do diagnóstico de uma crise da autoridade nesses países, não se expressou apenas no culto ao chefe, que emergiu em suas formas extremas no totalitarismo. Trata-se de um fenômeno político, operacional e simbólico que expressa uma nova maneira de construir e de nomear o social no século vinte que abrangeu também países liberais e capitalistas. Buscamos descortinar uma modalidade de transformação do social em todos os domínios de atividade.

\section{WHY SHOULD THE TWENTIETH CENTURY BE CALLED THE "CENTURY OF CHIEFS"?}

Keywords Abstract

History of authority; This article concerns the phenomenon of chieftaincy in

Cult of the chief;

Leadership;

History of practices; Social Transformation. the later igth and early 2oth centuries in France, Germany, the United States and the Soviet Union. It focuses on the emergence of a new discourse of command, the chief, authority and control of the masses. This discourse, which emerges from the diagnosis of a crisis of authority in these countries, was not only expressed in the cult of the chief, which assumed its more extreme forms in totalitarianism. It is a political, operational and symbolic phenomenon that expresses a new way of constructing and naming the social in the 2oth century, which also included liberal and capitalist countries. The article seeks to reveal a modality of the transformation of the social in all domains of activity. 